\title{
ÉTICA DO CONSUMO, CONSUMO CONSCIENTE E FELICIDADE
}

\author{
CONSUMPTION ETHICS, CONSCIOUS CONSUMPTION AND
}

\author{
HAPPINESS
}

\author{
Antônio Carlos Efing \\ Pontifícia Universidade Católica do Paraná - PUCPR - Curitiba - Paraná - Brasil \\ Alexandre Araujo Cavalcante Soares \\ Pontifícia Universidade Católica do Paraná - PUCPR - Curitiba - Paraná - Brasil
}

\begin{abstract}
Resumo: $O$ presente artigo busca discutir a necessidade de uma ética para 0 consumo. A revisão das correntes epistemológicas do tema, utilizado do método bibliográfico, aponta duas perspectivas para a explicação do ato de consumir em nossa sociedade, a saber: a perspectiva crítica e a perspectiva liberal. A ideia que permeia o presente estudo seria a possibilidade de construção de uma ética do consumo que permitisse a conciliação destas duas correntes em uma perspectiva única que atendesse aos anseios de uma sociedade justa e harmônica. Dessa forma, argumenta-se que o conceito de consumidor consciente, entendido como a soma dos conceitos de consumidor e cidadão é capaz de permitir uma nova forma de consumo em sociedade, que respeite as decisões individuais e permita a proteção em face dos efeitos danosos do consumo para o meio ambiente e ao próprio indivíduo. Adicionalmente, é defendida a ideia de que o consumo consciente pode resgatar a felicidade almejada no ato de consumir, ao privilegiar o usufruto ao possuir, ao valorizar os bens públicos e aos bens que não estão disponíveis no mercado.
\end{abstract}

Palavras-chave: Consumismo. Consumo Consciente. Desenvolvimento Socioambiental. Ética. Felicidade.

Abstract: This article discusses the need for ethics for the consumption. The review of epistemological current theme, used the bibliographic method, points out two prospects for the act of explanation consuming in our society, namely: the critical perspective and the liberal perspective. The idea that permeates this study is the possibility of building an ethic of consumption that would allow the reconciliation of these two currents in a unique perspective that would meet the aspirations of a just and harmonious society. Thus, it is argued that the concept of conscious consumer, understood as the sum of the consumer concepts and citizen is able to allow a new form of society in consumption that respects the individual decisions and enable protection against the harmful effects of consumption for the environment and the individual. Additionally it is argued that

Revista do Direito UNISC, ISSN: 1982-9957

Santa Cruz do Sul №. 48 | p. 52-69 | JAN-ABR 2016

https://online.unisc.br/seer/index.php/direito/index 
consumer awareness can redeem the desired happiness in the act of consuming, by privileging the enjoyment to possess, to value public goods and goods that are not available in the market.

Keywords: Consumerism. Conscious consumption. Environmental development. Ethics. Happiness.

\section{Introdução}

O presente estudo busca discutir a relação entre consumo e felicidade, e para tanto a necessidade de uma ética do consumo. Por certo, o entendimento da ética, enquanto aspecto que uma determinada sociedade utiliza para decidir o que é certo e errado, não pode ser concebido de forma deliberada. Contudo, a revisão das correntes epistemológicas do tema contribui para a explicação do ato de consumir em nossa sociedade, e sugere caminhos plausíveis para uma reconciliação das 'mazelas' que este consumo enseja.

O consumo apresenta-se como característica determinante na sociedade contemporânea, sendo inclusive esta sociedade descrita como 'sociedade de consumo' ou 'sociedade do espetáculo' (em termos mais usuais). Tal sociedade implica no surgimento de valores próprios do consumo, os quais representam um rompimento com valores construídos ao longo do desenvolvimento das sociedades, como coletivismo, cooperação e espírito comunitário. A sociedade de consumo, em sua forma atual, termina por estimular o individualismo, a indiferença e o próprio consumismo.

A academia tem dado a devida importância ao tema do consumismo, demonstrando as implicações deste comportamento para nossa sociedade. Pode-se definir o consumismo como o consumo pelo prazer de consumir, o qual assume aspecto patológico quando se torna compulsivo. Tal comportamento termina por instigar o consumo além do necessário (superconsumo) e um estilo de vida pouco preocupado com as consequências ambientais deste consumo.

Todavia, os estudos têm se limitado a mostrar os aspectos negativos do consumo e não necessariamente quais as perspectivas para a mudança de paradigma na sociedade. Adicionalmente, cabe destacar a crescente valorização da ética empresarial ou responsabilidade social empresarial, tanto no meio 
empresarial como acadêmico. Em comparação com essa, a ética do consumidor apresenta-se analisada ainda de forma incipiente.

Porém, a visão separada destas 'duas éticas' soa inadequada. A ética do consumo deve dar conta da relação de consumo, com seus respectivos coparticipes, e devendo a perspectiva de o consumidor definir o parâmetro para a ação empresarial.

A ideia a ser defendida é de que o consumo consciente visto de forma coletiva tem condições de permitir a autonomia do consumidor, bem como aplacar os danos os efeitos indesejados do consumo. Dessa feita, o ato de consumo configura-se também como ato político, rompendo com ideias de consumo no âmbito privado, em oposição a uma esfera estritamente pública.

Neste ensejo, o estudo se valerá do método bibliográfico para pautar a discussão, buscando coadunar os argumentos de autores com abordagem sociológica do tema com autores que privilegiam uma perspectiva econômica. Dessa forma, as seções seguintes buscam, inicialmente, discutir a ética do consumo; na sequência, apontar as disfunções que a atividade de consumo incorre, em sua atual condição; e finalmente, discorrer acerca do consumo consciente, destacando a possibilidade de este promover a autonomia e felicidade dos indivíduos e o desenvolvimento socioambiental.

\section{2. Ética do consumo}

De acordo com CORTINA (1999), apesar da relevância do consumo em nossa sociedade, as abordagens éticas do tema são escassas, muito provavelmente pela percepção de que tal assunto não seja digno da Ética. Todavia, a autora, a exemplo de outros autores como Don SLATER (2002) e Albert HISCHMANN (1998), identifica claramente duas tradições de pensamento filosófico sobre o tema, as quais podem ser sintetizadas como tradições: critica e liberal.

A partir do texto de Cortina, a tradição crítica remete aos estudos da sociedade consumista a partir dos autores da teoria da cultura de massa, como Horkheimer, Adorno, Marcuse e Galbraith. A tradição liberal, por seu turno, re- 
flete a "exaltação do consumo como exercício autêntico da autonomia pessoal por parte de certas 'éticas do capitalismo"' (CORTINA, 1999, p. 36).

A questão central nas duas tradições é a autonomia. Na primeira, entende-se que o indivíduo tem sua vontade compelida pelo sistema produtivo, o qual determina suas prioridades de consumo, assim como gera necessidades fúteis. Na segunda, a autonomia do indivíduo é soberana, e sua decisão (individual) de consumo determinará o sistema produtivo, o qual se subjuga a esta vontade.

Nesse esteio, SLATER (2002) nos provoca com a metáfora do consumidor enquanto "herói ou idiota", na qual pode se depreender tanto que o consumidor é o herói da modernidade, superando o conceito de cidadão, pois além dos direitos e deveres constitucionais, por meio de sua renda determina os bens e fornecedores que figurarão no mercado. Por outro lado, é possível entender o consumidor como um mero joguete, ou idiota, na mão do sistema produtivo, o qual o induz a crer que suas escolhas são autônomas, mas que em verdade são decididas pelo sistema.

Outro aspecto importante da ética do consumo, para além da questão da autonomia, refere-se às implicações do consumo para os indivíduos. $O$ ato de consumo não se funda em si mesmo, pois concerne na busca de bem-estar e felicidade. Dessa forma, vários autores discutem a lógica do consumo.

De acordo com LIPOVETSKY (2007), o consumo deixa de ser um mero ornamento de status com única função de delimitar estrutura social para iterarse na própria dinâmica da vida das pessoas. Nesse esteio, na sociedade contemporânea, surge o consumo estritamente particular com vistas a aplacar aos anseios individuais. Para Lívia BARBOSA (2006), a ética das sociedades de consumo funda-se na noção de consumo particular, a qual dispensa o agir em prol da comunidade, bem como a aprovação social do ato de consumo.

Todavia, e a despeito da lógica de motivação individual do consumo, resulta do consumo consequências sociais indesejadas, como poluição e perda da qualidade de vida (o que os economistas denominam de externalidades negativas de dados sistema produtivo), assim como disfunções sobre o próprio individuo consumidor, como consumismo, endividamento e angústia e insatis- 
fação. Ou seja, a promessa de bem-estar e felicidade proporcionada pelo consumo não resta cumprida.

De acordo com TORRES (2012), vários estudos demonstram de forma empírica que o aumento dos bens materiais não corresponde necessariamente a um aumento da felicidade. Nesse entendimento, cabe destacar os conceitos de felicidade objetiva e subjetiva. A primeira responde a abordagens psicológicas passíveis de serem observadas, apuradas e medidas em condições numéricas, de acesso a bens de consumo e seus reflexos em estatísticas sociais, ambientais e econômicas como nível de renda, expectativa de vida e outros. A segunda, por seu turno, recorre a "avaliação dos indivíduos com relação à felicidade ou satisfação com a vida, em que se observa a presença das dimensões cognitivas e emocionais no seu processo de julgamento" (TORRES, 2012, p. 18). Nesse contexto, a felicidade aqui tratada é a felicidade subjetiva, haja vista que o consumo, por definição, leva a felicidade objetiva.

Outra perspectiva sobre a ética do consumo pode ser depreendida do pensamento de Bauman. De acordo com AQUINO (2011), Bauman define ética como um esforço típico da era moderna, calcada na razão e na ciência, de eliminar ambiguidades morais das decisões humanas. "Na medida em que surge a dificuldade, ter-se-á apenas uma resposta para sua solução. Essa resposta precisa ser enunciada (senão, imposta) pela autoridade ética a partir do conhecimento o qual é guiado pela razão lógica" (AQUINO, 2011, p. 38). As autoridades seriam o Estado, o Judiciário, a Religião, e a estas caberiam a incumbência de decidir sobre quais medidas práticas a responsabilidade exige, já que seriam dotadas de autoridade ética. Tal acepção conduz ao conceito de ética sem moral, já que o juízo de valor individual não seria mais necessário e desejável.

O autor alude ao fato da diminuição da responsabilidade do indivíduo, que a partir de uma lista definida de deveres e de obrigações, proporcionou, em certa medida, alívio, diminuindo a angústia da escolha. Todavia, e longe deste modelo ser ideal (haja vista as atrocidades cometidas em nome de institutos supra individuais como o nazismo), tal sistema tende na pós-modernidade a transferir a responsabilidade de fornecimento de regras éticas, outrora mono- 
polizadas pelo Estado, para o mercado. O que nos conduz às imperfeições já comentadas.

Tal movimento levaria a uma moral sem ética, já que as decisões seriam tomadas "em uma legitimidade das emoções - um sentir algo com o Outro, um "ser-para"1 - na qual justifica a responsabilidade moral por meio da Alteridade e proximidade" (AQUINO, 2011, p. 46).

A partir destas considerações, procura-se neste ensaio, conciliar tais tensões em um modelo ético de consumo, como a inclusão no tema do fenômeno contemporâneo do consumo consciente.

\section{Disfunções da sociedade de consumo}

É necessário estabelecer o recorte temporal de nossa análise, a qual coincide o período da revolução industrial. Não se quer, com isso, asseverar que antes desse momento histórico, o consumo não tenha aspectos negativos na sociedade, contudo, é com o início da industrialização que as disfunções do consumo assumem as feições atuais. Tal acepção fica patente na fala de RIFKIN (1999), quando afirma que todo o lixo produzido pela sociedade advém da era industrial, pois antes desta, tudo era aproveitado, até mesmo os ossos dos animais eram utilizados nas sociedades tribais enquanto objetos de ornamentação.

A análise do consumo pode ser resumida em uma 'rápida' mudança na forma como as empresas se apresentam à sociedade, de produtoras de bens imbuídos de facilidades, da qual não se discutia a utilidade como: gorduras enlatadas, saponáceos, e mesmo automóveis, para bens com elevado nível de hedonismo e necessidade contestável. Não há dúvida que o início desse desenvolvimento trouxe felicidade para as pessoas, tanto do ponto de vista objetivo quanto subjetivo. Pensa-se na praticidade que tais bens adquiridos a baixo custo trouxeram para a vida das pessoas.

O desenvolvimento das organizações industriais e as atividades de marketing que se seguiram, em larga medida seguiram a lógica de atender necessidades de forma conveniente, ou seja, aumentar o bem-estar do consumidor.

\footnotetext{
${ }^{1}$ A expressão denota uma visão de mundo pautada na percepção do outro, um agir que priorize o bem comum a partir do outro. Nesse caso, os padrões de conduta sujem a partir das interações, não seguindo conceitos ideais e exógenos.
} 
Talvez o melhor exemplo dessa tendência sejam os alimentos prontos ou congelados, que dispensam preparação e cozimento. Toda esta conveniência gera aspectos negativos do ponto de vista social, como aumento do número de embalagens, aumento nas emissões de dióxido de carbono para transportes cada vez mais distantes, aumento no uso de energia para exposição em varejo e armazenamento em casa; e de ponto de vista individual incentivo a obesidade, aumento da ingestão de ingredientes químicos, como açucares, conservantes e estabilizantes, e diminuição na ingestão de fibras e nutrientes.

Ainda, pode-se adicionar a esta extensa lista o desincentivo ao consumo de itens locais, bem como o desconhecimento da origem do item a ser consumido, o qual pode ferir as regras de comércio justo, explorar mão de obra infantil, ou regime assemelhado a escravidão, bem como incorporar insumos que agridam o meio ambiente. Dessa assertiva, depreende-se que o exacerbo da conveniência leva a uma inconveniência do ponto de vista da consciência ambiental.

Em outra seara, as atividades empresariais e mercadológicas, desenvolvem aspectos hedônicos e relacionados a status por meio do desenvolvimento de marcas. Tal movimento incorre em outros dissabores para o consumidor. Inicialmente, as "marcas" cobram preços extras, não em função de custos efetivos, mas sim como um elemento próprio de diferenciação. Com efeito, a busca por níveis de consumo incrementais e novidades, torna o hábito de consumir uma busca em si mesmo.

Desta vez, o exemplo mais apropriado concerne na indústria da moda, a qual claramente buscar criar demandas desnecessárias a partir da manipulação das carências e desejos humanos. Questiona-se número adequado de roupas e sapatos que um cidadão médio teria necessidade, e provavelmente não se teria resposta objetiva. Agora, perguntemos se há necessidade de roupas novas, e a resposta parece inequívoca: sim.

Caberia aqui neste ponto, a discussão sobre as técnicas comerciais criarem demanda ou apenas atenderem desejos de seres humanos, os quais seriam carentes por natureza. Com efeito, se teria um bom debate, e mesmo que se pendesse para a segunda opção, alguém poderia argumentar que não caberia às empresas educarem ou resolverem o problema humano de carência. 
Dessa forma, evitar-se-á tal embate, e tomar-se-á com referência que as empresas atendem necessidades, genuínas ou não, sem, contudo, pesar os efeitos individuais ou sociais de tal perspectiva.

Dentre os vários estudos que buscam avaliar quais os impactos que as organizações geram para a sociedade, temos o estudo de WAGNER, BICEN e HALL (2008), que propõem o conceito de Irresponsabilidade Social Corporativa (ISC) enquanto construto, constituído a partir de um conjunto de diferentes dimensões: regras sociais, discriminação de empregados, condições de trabalho, desonestidade, políticas de preços, ambiente natural, benefícios para empregados, exploração de mão de obra em países em desenvolvimento, salários dos empregados, impacto nos negócios locais, impacto no nível de emprego local, material de comunicação ofensivo, benefício de economias estrangeiras, e práticas de vendas.

JONES, BOWD e TENCH (2009) apontam um modelo conceitual para entendimento do tema, no qual os construtos Responsabilidade Social Corporativa (RSC) e ISC configuram extremos ao longo de um contínuo. O modelo destaca elementos externos à organização (Diversidade e Igualdade de oportunidades, Governança Corporativa, Tecnologia, e Meio Ambiente), e elementos internos (Envolvimento Comunitário, Lucros, Clientes e Fornecedores, Colaboradores, e Comportamento Ético).

A proposição dos autores indica que as ações e práticas empresariais podem conter diferentes graus de responsabilidade e irresponsabilidade. Dessa forma, uma organização pode apresentar "boas" práticas em determinado aspecto, porém práticas danosas em outro conjunto de ações. Ainda de acordo com os autores, existe considerável hiato entre o que é dito e feito pelas corporações. As empresas tendem a apregoar o que fazem de "bom" e a omitir-se em relação ao que fazem de danoso. Nas palavras dos autores, o modelo conceitual permite uma melhor visualização de tal lacuna:

"O que eles dizem" deve ser equiparado com a Responsabilidade Social Empresarial e "O que eles fazem" pode ser equiparado com Irresponsabilidade Social Empresarial. Existe um hiato entre retórica gerencial e como a realidade é experimentado e vivido na prática. O modelo Irresponsabilidade e Responsabilidade conduz a gestão a um reconhecimento da companhia (JONES; BOWD; TENCH, 2009, p. 305-306). 
De forma geral, a ideia dos autores é situar as empresas dentro do contínuo (ISC-RSC), não sendo a responsabilidade uma questão de opção para as organizações (ser ou não ser responsável), e sim uma alternativa à condição de irresponsável, configurando a seguinte questão fundamental: ser responsável ou ser irresponsável?

Contudo, o rol de danos causados aos consumidores não é exaurido nas descrições acima. É cabida a abertura de um novo flanco de 'mazelas' relacionados à psique humana. $\mathrm{O}$ mal-estar com a impossibilidade de consumir conquanto nossa vontade deseje, nos parece já assimilado pela sociedade. Todavia, problemas relacionados à depressão e dificuldades de convivência social parecem ser características de uma sociedade individualizada, consumista e materialista.

As atividades sociais que cumpriam funções específicas de aplacar questões existenciais, como religião, política e engajamento em temas comunitários, são menos valorizadas em nossa sociedade. O tempo livre, conseguido com as facilidades que os bens materiais proporcionam, é direcionado para novas atividades produtivas no intuito de gerar mais renda, eliminando o tempo disponível para usufruto dos bens já acumulados e dos que porventura venha a incorporar.

Aliado a tais questões, temos o fenômeno recente do endividamento, no qual os cidadãos instigados a consumir e influenciados pelas facilidades da concessão de empréstimos, e dificuldade de se planejarem financeiramente, incorrem em dívidas além de suas capacidades de pagamento. Todavia, e a despeito de tal fato remeter a aspectos no âmbito particular, tem-se evidências de que a condição de endividado conduz a quadros patológicos, com implicações na saúde psicológica do indivíduo.

Em suma os aspectos relacionados nesta seção sugerem um esgotamento no modelo de sociedade em que se vive. Todavia, a mesma sociedade que permitiu todo esse desvirtuamento, cria em seu seio as bases de uma nova perspectiva de vida em sociedade, a partir de própria reflexão crítica do modelo em voga. 


\section{Consumo consciente e felicidade}

O consumidor consciente, que na definição de EFING (2011, p. 125) "reflete a necessidade de os consumidores (de produtos e serviços) passarem a ser agentes de 'controle crítico' do desenvolvimento sustentável, (...)”, surge no esteio das práticas ativistas dos cidadãos, com forte ênfase na defesa do meio ambiente e animais, e na proteção conta abusos na relação das empresas com o consumidor. Dessa forma, podemos destacar dois aspectos que balizam o fenômeno do consumo consciente: o uso e disseminação de informação e a legislação protetiva do consumidor, esta última específica para o caso brasileiro.

Nestes termos, cabe a discussão de como o conceito evolui de uma dimensão estritamente ambiental para um conceito mais amplo. Nesse intento, é elucidativo o ponto de vista de PORTILHO (2005):

\footnotetext{
O consumidor verde foi amplamente definido como aquele que, além da variável qualidade/preço, inclui em seu "poder de escoIha", a variável ambiental, preferindo produtos que não agridam ou sejam percebidos como não-agressivos ao meio ambiente. Dessa forma, o movimento de consumo verde enfatizou a habilidade dos consumidores agirem em conjunto, trocando uma marca $X$ por uma marca $\mathrm{Y}$, ou mesmo parando de comprar um determinado produto, para que os produtores percebessem as mudanças na demanda. As ações e as escolhas individuais motivadas por preocupações ambientais passaram a ser vistas como essenciais, e o consumidor como o responsável, através de suas demandas e escolhas cotidianas, por mudanças nas matrizes energéticas e tecnológicas do sistema de produção (PORTILHO, 2005, p. 03).
}

Todavia, essa ideia de "comprar um futuro melhor" mostrou-se inadequada, tornando uma grande armadilha, haja vista que o consumo verde foca apenas uma parte da questão, no caso a tecnologia, e não os elementos da cultura do consumo propriamente, como o consumismo.

Nesse sentido, a proposta de consumo verde é fundada na ideia de que se os consumidores tiverem conhecimento e informações razoáveis, eles terão a condição necessária de exercer a "consciência ambiental" que os conduzirá a atitudes e comportamentos benignos. Como exemplo dessas estratégias temse os programas de eco-rotulagem, os quais tornaram-se a principal ferramenta desta perspectiva. 
Nesse esteio, a prática do consumo verde converteu-se, ainda, em uma espécie de transferência da atividade regulatória do Estado para o mercado, e desta para o consumidor, por meio de suas escolhas de consumo. Assim, ambos - governos e empresas - "encorajariam a responsabilidade individual, implícita ou explicitamente, através de referências ao poder do consumidor, ao "bom cidadão" ou à valorização da contribuição pessoal de cada um, transferindo a responsabilidade para um único lado da equação: o indivíduo" (PORTILHO, 2005, p. 03).

Dessa forma, e entendendo a ideia do consumo verde enquanto restritiva, eis que surgem propostas que valorizem cada vez mais as ações coletivas e efetivas mudanças institucionais (mais do que as tecnológicas, econômicas e comportamentais), as quais concernem na proposta do consumo sustentável.

A partir desta concepção, as ações deslocam-se de uma esfera individual para incorrer em compromisso com a moralidade pública, por meio de ações coletivas, bem como pela implementação de políticas multilaterais de regulação, tanto da produção quanto do consumo, o que permitiria um sistema de compartilhamento de responsabilidades entre indivíduos, comunidade e Estado.

\footnotetext{
A estratégia de produção e consumo limpos ou verdes começa a perder espaço para uma estratégia de produção e consumo sustentáveis. O meio ambiente deixou de ser relacionado apenas a uma questão de como usamos os recursos (os padrões), para também estar vinculado à preocupação com o quanto usamos (os níveis); portanto, um problema de acesso, distribuição e justiça (PORTILHO, 2005).
}

Outro trabalho no qual se permite vislumbrar a evolução do conceito é apresentado por CASALI (2011). No texto, a autora considera os consumidores como uma força para o bem, e alinha-se como determinados autores, que utilizam o conceito de "Responsabilidade Social do Consumidor" (RSCons). Nesta perspectiva, mais ampla e coletivista, "o consumidor se comporta de maneira ética não apenas considerando beneficiar a si próprio, mas visando o bem da coletividade" (CASALI, 2011, p. 04).

Em seu estudo, CASALI (2011) identificou quatro categorias de Responsabilidade Social do Consumidor, a saber: 
1. Comportamento altruísta: aquele que o indivíduo, de forma voluntária e consciente, exerce com a intenção de ir além de apenas satisfazer suas necessidades, considerando o bem-estar dos stakeholders envolvidos, bem como da coletividade em geral;

2. Comportamento ambientalmente sustentável: Aquele em que o indivíduo pauta suas escolhas de consumo na sustentabilidade ambiental, isso inclui uma gama de possibilidades desde evitar comprar de empresas que não incorporam em suas práticas preocupações ambientais, até uma contribuição de forma mais direta adotando em seu cotidiano atividades de reciclagem ou de reutilização de materiais;

3. Comportamento ativista: Qualquer ato que impulsiona o consumidor a romper a inércia tradicional para numa postura mais ativa manifestar no consumo suas preocupações de natureza social, ambiental e/ou ética;

4. Comportamento ético na relação de troca: Aquele que o indivíduo exerce zelando pela honestidade na relação de troca em si.

A partir destes recortes, resta discutir a dimensão da cidadania no conceito de consumo consciente. Ademais, a maioria dos autores que versam sobre o tema o definem em termos da díade: consumo e cidadania. Na concepção de CHAUDHURY e ALBINSSON (2015), os autores que antagonizam os conceitos de consumidor e cidadão, incorrem em uma dicotomia míope, já que na realidade os domínios estão interligados.

A cidadania é, portanto, um espaço não bem delimitado já que as pessoas não compartimentalizam perfeitamente suas vidas em atividades de consumo e cívicas.

A noção de "vida política" de Giddens é conceituada como relativa às escolhas que as pessoas fazem todos os dias e às políticas de interesses pessoais, na qual o indivíduo se vincula às instituições. Em outras palavras, as práticas de consumo são processos que ligam os indivíduos a sistemas maiores de provisão, ligando mundos privados e públicos.

A partir das obras de teóricos sociais, como Bauman, Beck e Giddens, a orientação para o cidadão-consumidor reflete as práticas definidas no presente de como se é, se pensa que se é, e como se quer ser por meio de nossas prá- 
ticas de aquisição de bens no mercado. Por exemplo, o consumidor que compra cosméticos sem testes em animais, exerce simultaneamente o papel de consumidor que busca realçar a beleza individual, e de cidadão, pela postura cívica sobre os direitos dos animais.

De acordo com CARR e outros (2012), o comportamento de consumo consciente surge como resposta a um recrudescimento do consumismo. Enquanto muitos americanos têm abraçado o "novo consumismo", outros têm focado sua energia em aprender a resistir, mesmo no silêncio. Na verdade, o anticonsumismo é um sentimento subjacente a comportamentos como downshifting (redução) e simplicidade voluntária, bem como práticas discursivas, tais como interferência cultural, visando a expressar descontentamento para com os anunciantes e ações de sensibilização para práticas empresariais antiéticas.

Indo além do anticonsumismo como um remédio para os males sociais provocados pelo "novo consumismo", estudiosos identificaram também uma tendência paralela para o consumo consciente, definida como:

Qualquer escolha sobre produtos ou serviços feita como uma maneira de expressar valores de sustentabilidade, justiça social, responsabilidade corporativa, ou os direitos dos trabalhadores e que leva em conta o contexto mais amplo da produção, distribuição, ou impactos de produtos e serviços (CARR e outros, 2012, p. 224).

Aqui, o foco é menos sobre a dimensão de redução do consumo, e mais do exercício de consumo consciente, isto é, considerando como suas ações terão impacto no meio ambiente e no bem-estar dos outros.

Consumidores conscientes envolvem-se em boicotes, procuram produtos eticamente certificados, e geralmente estão dispostos a gastar mais em produtos que cabem na sua visão de mundo. Na verdade, a politização das decisões de compra do cotidiano pode ser vista como uma ilustração de construção de identidade que está sendo realizado por meio da integração do desejo do consumidor e responsabilidade cívica.

Ainda na lógica de questionar os trabalhos acadêmicos que sugerem excludentes os aspectos das preocupações cívicas e interesse dos consumidores, o trabalho de Atkinson (2012) aponta simplista o raciocínio que reduz o consumo a um mal social que seria a antítese dos valores republicanos "reais". Os autores que endossam a seara menos crítica, argumentam que a fusão da 
política e do consumo tem o potencial para inspirar a solidariedade e o propósito comum, capacitar os indivíduos no mercado, oferecer às pessoas uma maneira fácil e agradável para decretar seus deveres cívicos, e em conformidade com as normas e realidades de uma sociedade pós-moderna de direitos orientada (ATKINSON, 2012).

Corroborando com estes pressupostos, os dados do trabalho empírico conduzido pela autora aduzem que esses consumidores, no caso os conscientes, colhem vários benefícios privados de suas escolhas socialmente conscientes (autenticidade, imersão social, empoderamento, e auto realização), além de ajudar a garantir virtudes públicas mais amplas, como um ambiente limpo ou os direitos dos trabalhadores.

Como os benefícios figuram aspectos cognitivos e emocionais, é possível supor que tal comportamento torne a experiência de compra mais gratificante, o que coaduna com a suposição inicial de que o consumo consciente tem potencial de restaurar, ou contribuir, para a felicidade subjetiva perdida na práxis da sociedade de consumo. A ideia subjacente é de que a percepção de que 0 ato de consumo gera incremento positivo na sociedade, repercutirá em benefício extra para o consumidor.

Por tudo isso, uma vida mais simples e frugal é a iniciativa imediata que todos podem tomar, não significando, entretanto, que esta nova postura seja contrária ao bem-estar e felicidade, mas que é necessário valorizar as coisas que não têm preço, como os bens públicos, bem como tornar as decisões do dia a dia imbuídas de uma reflexão mais acurada.

Na concepção de TESCAROLO e DARÓS (2012), a ética assume, nesse novo cenário, um novo sentido radical: não só como responsabilidade individual, mas também coletiva, levando em conta as consequências das intervenções humanas no mundo. Isso implica a adoção de uma dupla concepção contemporânea de ética: como óptica "dos valores irrenunciáveis" e como "negociação dos consensos com vistas a normas jurídicas e a criação de instituições, que terão efeitos auto reguladores na dinâmica social das sociedades complexas".

Adicionalmente, e para retomar a discussão da felicidade, volta-se ao trabalho de CORTINA (1999). De acordo com a autora, para o consumo se re- 
ferir a essa dimensão de "bom", no sentido de adequado, deve recorrer a uma noção de que tem sido feita desde os anos cinquenta em estudos de bemestar: a noção de "qualidade de vida". Recorrer à noção de "felicidade" seria, na opinião da pesquisadora, inútil, já que felicidade é muito pessoal e pouco suscetível de ser objetivada. Qualidade, por seu lado, embora certamente tenha um componente pessoal inegável, tem algumas variáveis que podem ser objetivadas.

Ainda de acordo com Cortina, fazendo menção a Scitovsky, a maioria das ações que gratifica os seres humanos, ou que afetam a suas auto realização, podem ser feitas sem produtos com um mercado. Outras ações terão a necessidade, mas não são mais geradoras de felicidades as que precisam de maior número de produtos ou as que são mais caras. Ler, praticar esportes em um clube, ouvir música, partilhar uma refeição agradável, são atividades que podem ajudar a levar uma vida boa dentro dos preceitos de prudência.

Nesse sentindo, convém destacar porque Aristóteles distinguiu entre economia e crematística. A economia trata da gestão da casa, enquanto crematística é buscar o máximo benefício com a troca. "Procurar o máximo" implica em não estar satisfeito com o suficiente, e sim acorrentado a uma busca indefinida, sem fim, sem limites, para a qual nunca pode ser alcançada a satisfação. A satisfação é alcançada com as atividades gratificantes por si mesmas, que não vinculam a pessoa a uma busca interminável.

\section{Conclusão}

A partir dos autores utilizados na discussão do tema, é possível tecer algumas considerações finais que respondem ao intento do estudo. Inicialmente, cabe destacar que apesar do tema 'ética do consumo' não ser recorrente na literatura, encontrou-se duas correntes explicativas que embasam seu entendimento, a saber: crítica e liberal. A corrente crítica enfatiza as disfunções do consumo, enquanto a liberal enaltece a liberdade de escolha do consumidor no livre mercado.

No rol de 'mazelas' relacionadas ao consumo, destaca-se o mal-estar com a impossibilidade de consumir conquanto nossa vontade deseje, a não 
compreensão da real necessidade de consumo, e as implicações sociais e ambientais que o consumo exacerbado enseja. Adicionalmente, uma sociedade individualizada, consumista e materialista, em detrimento de valores comunitários e cooperativos, tende a apresentar maiores problemas de convivência e civilidade.

Assim, e buscando conciliar as virtudes da liberdade do mercado e aplacar as disfunções no ato de consumir, a ideia do consumo consciente surge como uma nova ética para o consumo.

Dessa forma, o consumo consciente remete ao conceito de consumo sustentável, que amplia a visão do consumo verde, ao valorizar cada vez mais as ações coletivas e efetivas mudanças institucionais. Ou seja, mais do que os padrões de consumo (tecnologia), os níveis de consumo devam ser revisados.

Adicionalmente, foram evidenciados benefícios adicionais que os consumidores conscientes colhem de suas escolhas socialmente conscientes, como autenticidade, imersão social, empoderamento, e auto realização, além de ajudar a garantir virtudes públicas mais amplas, como um ambiente limpo.

Supondo um bem coletivo e individual maior, é possível prever que o comportamento de consumo consciente torne a experiência de consumo mais gratificante, o que implica na capacidade de este comportamento restaurar, ou contribuir, para a felicidade subjetiva perdida na sociedade de consumo. A ideia subjacente é de a percepção de que o ato de consumo gera incremento positivo na sociedade, repercutirá em benefício extra para o consumidor.

Buscou-se, com o presente estudo, demonstrar, por meio da conceituação de autores e de evidências de pesquisa empíricas, a possibilidade de felicidade por meio do consumo consciente. Tomou-se como pressuposto, que os indivíduos, voluntária e invariavelmente, tendem a aderir a tais comportamentos conscientes de consumo. Todavia, são cabidas novas investigações que apontem a tendência ou não da sociedade em aderir tais atitudes.

\section{Referências}

AQUINO, Sérgio Ricardo Fernandes de. Ética e moral no pensamento de Bauman. Cadernos Zygmunt Bauman. v 1, no. 2, 2011, p. 35-47. 
ATKINSON, Lucy. Buying In to Social Change: How Private Consumption Choices Engender Concern for the Collective. ANNALS, AAPSS, 644, November, 2012.

BARBOSA, Lívia. Igualdade e meritocracia: a ética do desempenho nas sociedades modernas. 4ª edição, Rio de Janeiro: Editora FGV, 2006.

CARR, D. Jasun; GOTLIEB, Melissa R.; LEE, Nam-Jin; SHAH, DHAVAN V. Examining Overconsumption, Competitive Consumption, and Conscious Consumption from 1994 to 2004:Disentangling Cohort and Period Effects. ANNALS, AAPSS, 644, November, 2012

CASALI, Richélita do Rosário Brito. Responsabilidade Social do Consumidor: conceituação e proposta de mensuração. Dissertação de Mestrado. Programa de Pós Graduação em Administração. CCSA (UFPB), João Pessoa, 2011. $216 f$.

CHAUDHURY, Sarita Ray; ALBINSSON, Pia A. Citizen-Consumer Oriented Practices in Naturalistic Foodways: The Case of the Slow Food Movement. Journal of Macromarketing, Vol. 35(1), 2015, p. 36-52.

CORTINA, Adela. Ética del Consumo: por un consumo justo y de calidad. Claves de Razón Práctica, № 97, noviembre, 1999, p. 36-42.

EFING, Antônio Carlos. Fundamentos do Direito das Relações de Consumo. 3a edição. Curitiba: Juruá Editora, 2005.

HISCHMANN, Albert. De consumidor a cidadão: atividade privada e participação na vida publica. São Paulo: Editora Brasiliense, 1998.

JONES, Brian; BOWD, Ryan; TENCH, Ralph. Corporate irresponsibility and corporate social responsibility: competing realities. Social Responsibility Journal. vol. 5, no. 3, 2009, p. 300-310.

LIPOVETSKY, Gilles. A felicidade paradoxal: ensaio sobre a sociedade de hiperconsumo. São Paulo: Companhia das Letras, 2007. 
PORTILHO, Fátima. Consumo sustentável: limites e possibilidades de ambientalização e politização das práticas de consumo. Cad. EBAPE.BR, Rio de Janeiro, v. 3, n. 3, p. 01-12, 2005.

RIFKIN, Jeremy. O século da biotecnologia: a valorização dos genes e a reconstrução do mundo. São Paulo: Makron Books, 1999.

SLATER, Don. Cultura do consumo e Modernidade. São Paulo: Nobel, 2002.

TESCAROLO, Ricardo; DARÓS, Lauro. Transformação e formação: por uma ética planetária. IX ANPED SUL. Seminário de Pesquisa em Educação da Região Sul. 2012

TORRES, Polyanna de Arruda. Em busca da felicidade: uma pesquisa sobre $o$ bem-estar no consumo. Dissertação de Mestrado. Programa de Pós Graduação em Administração, CCSA (UFPB), João Pessoa, 2012. $157 f$.

WAGNER, Tillmann; BICEN, Pelin; HALL; Zachary R. The dark side of retailing: towards a scale of corporate social irresponsibility. International Journal of Retail \& Distribution Management. vol. 36, №. 2, 2008, p. 124-142. 